\title{
Qualidade fisiológica de sementes de soja (Glycine max. L.) durante o beneficiamento $^{1}$
}

\author{
Physiological quality of soybean (Glycine max. L.) seeds during to \\ processing
}

\author{
Reginaldo Pedro da Silva²; Itamar Rosa Teixeira ${ }^{3 *}$; Ivano Alessandro Devilla \\ Ricardo Caetano Rezende ${ }^{4}$; Gisele Carneiro da Silva ${ }^{5}$
}

\section{Resumo}

$\mathrm{Na}$ busca de sementes de alto padrão de qualidade, a fase de beneficiamento configura-se como importante etapa. Objetivou com este trabalho avaliar a qualidade fisiológica de sementes de cultivares de soja durante o processo de beneficiamento. Empregou-se o delineamento experimental inteiramente casualizado em esquema fatorial 4 × 5, com quatro repetições. Os tratamentos foram constituídos de quatro cultivares de soja (Vencedora, Emgopa-313, Luziânia - não transgênicas e Valiosa - transgênica) coletadas em cinco pontos de amostragem $\left(1^{\circ}\right.$ - secador; $2^{\circ}$ - elevadores de caneca número $1 ; 3^{\circ}$ - elevadores de caneca número $2 ; 4^{\circ}$ - elevadores de caneca número 3 e $5^{\circ}$ - espiral). A qualidade fisiológica das sementes foi avaliada pelos seguintes testes: germinação, primeira contagem, envelhecimento acelerado, condutividade elétrica e tetrazólio (viabilidade e vigor). As sementes de soja das cultivares Emgopa-313, Valiosa - RR e Luziânia apresentaram qualidade fisiológica superior à Vencedora, em todas as etapas do beneficiamento. Para as sementes da cultivar Vencedora, o grande número de elevadores de caneca no decorrer das etapas de secagem e no beneficiamento propiciou aumento na porcentagem de dano mecânico à semente.

Palavras-chave: Produção de sementes, classificação, germinação, vigor

\begin{abstract}
Processing is an important phase in the seed industry. It encompasses important steps to attain seed quality and high performance. The objective of this work was to evaluate the physiological quality of soybean seed cultivars during important steps of that process. A completely randomized design in a $4 \mathrm{x}$ 5 factorial arrangement with four replicates was used. Samples of three soybean cultivars (Vencedora, Emgopa 313, Luziânia - non transgenic and one genetically modified - Valiosa) were drawn in five points of the processing chain: $1^{\circ}$ - seed dryer; $2^{\circ}$ - bucket elevator number $1 ; 3^{\circ}$ - bucket elevator number $2 ; 4^{\circ}$ - bucket elevator number 3 ; and $5^{\circ}$ - seed spiral separator. The following tests were performed: germination, first count, accelerated aging, electrical conductivity and tetrazolium (viability and vigor). Results obtained indicated that seeds from cultivars Emgopa-313, Luziânia and Valiosa - RR
\end{abstract}

\footnotetext{
1 Parte da Dissertação apresentada à Universidade Estadual de Goiás, UEG. UnUCET como um dos requisitos do curso de Mestrado em Engenharia Agrícola.

2 Eng $^{\mathrm{o}}$ Agr $^{\mathrm{o}}$, Mestre em Eng. Agrícola, Universidade Estadual de Goiás, UEG. UnUCET. BR 153, Km 98, Campus Henrique Santillo, CEP 75001-970, Anápolis, GO.E-mail: aedys@ig.com.br

3 Eng ${ }^{\circ}$ Agr ${ }^{\circ}$, Prof. Dr. do curso de Eng. Agrícola da Universidade Estadual de Goiás, UnUCET. E-mail: itamar.texeira@ueg.br

4 Eng. Agrícola, Prof. Dr. do curso de Eng. Agrícola da Universidade Estadual de Goiás, UEG. UnUCET. E-mail: ivano.devilla@ gmail.com; rezende@ueg.br

5 Eng $^{\mathrm{O}}$ Agr $^{\circ}$, Mestranda em Agronomia, Universidade Federal de Goiás. Rodovia Goiânia-Nova Veneza, Km 0, Campus Samambaia, CEP 74001-270, Goiânia, GO. E-mail: gisele.agronomia@hotmail.com

* Autor para correspondência
} 
presented physiological quality higher than Vencedora, in all stages of processing. To cultivar seeds of Vencedora, the number of elevators mug during the stages of drying and processing time increased the percentage of mechanical damage to seed.

Key words: Seed production, classification, germination, vigor

\section{Introdução}

A cultura da soja (Glycine max (L.) Merrill) é considerada atualmente uma commodity no Brasil, representando um dos principais produtos da pauta de nossas exportações. Na safra 2009/10, o Brasil produziu 68,7 milhões de toneladas, em uma área de 23,5 milhões de hectares (CONAB, 2010). Apesar da importância, a sua produtividade tem oscilado, dependendo do ano e da região de cultivo, em que o uso de sementes de qualidade inferior configura-se como um dos fatores responsáveis por este fato.

Antes das sementes de soja serem submetidas ao processo de beneficiamento, devem apresentar teor de água em torno de $11 \%$, havendo dessa forma, a necessidade do uso de secagem artificial para o caso de colheita de lotes de sementes com teor de água entre 18 a 22\% (CARVALHO; NAKAGAWA, 2000; PESKE; VILLELA, 2003), como normalmente acontece por ocasião da colheita.

O beneficiamento constitui uma etapa importante na produção de sementes de qualidade. Compreende um conjunto de operações às quais a semente é submetida desde a recepção da unidade de beneficiamento até a sua embalagem e distribuição (PESKE; LUCCA FILHO; BARROS, 2006). Estas etapas visam à melhoria das características físicas de um lote de sementes, já que o máximo da qualidade está em função direta das condições de produção no campo.

O beneficiamento tem como objetivo separar dos lotes os materiais indesejáveis como impurezas, sementes de plantas daninhas, sementes imaturas, mal formadas e deterioradas, e as atacadas por fungos e insetos (CARVALHO; NAKAGAWA, 2000). Esta separação se torna possível quando existem diferenças de características físicas entre as sementes e o material indesejável. Sendo assim, o beneficiamento pode manter as características referentes à qualidade dos lotes de sementes produzidas no campo, no tocante as sua qualidade física, fisiológica e/ou sanitária.

Contudo, como o caminho que a semente percorre durante o processo de beneficiamento é longo e comumente ocorrem injúrias mecânicas causadas por agentes físicos durante o manuseio das mesmas, que além de provocarem prejuízos diretos, dão abertura a agentes patogênicos altamente deletérios (MACHADO, 2000). Essas injúrias mecânicas causadas pelo beneficiamento ocorrem por contatos das sementes com superfícies rígidas, que provocam quebras, trincas e abrasões, ocasionando redução na germinação e no vigor (KRZYZANOWSKI; VIEIRA; FRANÇA NETO, 1999), além de dificultar as operações de beneficiamento.

Vários pesquisadores, dentre os quais Naplava, Weingartmann e Boxberger (1994) e Peterson, Perdomo e Burris (1995) e Pacheco, Castoldi e Alvarenga (1996), constataram injúrias mecânicas em sementes provocadas pelo beneficiamento, proporcionando aumento do número de plântulas fracas e anormais, maior susceptibilidade a microrganismos, maior sensibilidade ao tratamento químico e redução do potencial de armazenamento. Além disso, por causa dos efeitos cumulativos das injúrias mecânicas, a germinação, o vigor e a produtividade foram irreversivelmente afetados.

Segundo Andrade et al. (1999) a injúria mecânica e misturas de cultivares são apontadas pelos tecnologistas como os mais sérios problemas da produção de sementes por se constituírem em uma questão praticamente inevitável, em virtude das principais fontes desses danos se encontrarem em todas as etapas do processo produtivo (colheita, beneficiamento, armazenamento e transporte).

No caso da semente de soja têm-se um agravante 
pelo fato desta ser particularmente susceptível ao dano mecânico, uma vez que o eixo embrionário está situado sob tegumento pouco espesso, que praticamente não oferece proteção (MARCOS FILHO, 2005). Ressaltase, porém, a presença de variabilidade genética para a susceptibilidade da semente de soja ao dano mecânico (CARBONELL et al., 1993), sendo vários os trabalhos de pesquisa que comprovam isso (PAULSEN; NAVE, 1981; COSTA; KUENEMAN; MONTEIRO, 1987; CARBONELL; KRZYZANOWSKI, 1995). Estudos recentes confirmaram a correlação positiva entre o teor de lignina e a resistência do tegumento de sementes de cultivares de soja resistente a dano mecânico (ALVAREZ et al., 1997; FLOR et al., 2004).

Nesse contexto, estudos investigativos sobre qualidade de sementes produzidas pelos atuais genótipos de soja durante as etapas de beneficiamento, são necessários, objetivando o fornecimento de informações pormenorizadas à indústria sementeira para o controle de qualidade de sementes produzidas, especialmente para a região Centro-Oeste. Assim, sabendo que o beneficiamento é importante fonte de injúria mecânica, devido, principalmente, às quedas sucessivas inerentes à operação, este trabalho visou avaliar a qualidade fisiológica de sementes de cultivares de soja em diferentes etapas do processo de beneficiamento.

\section{Material e Métodos}

As sementes das cultivares utilizadas no ensaio foram provenientes de campos de produção na safra $2007 / 2008$, conduzidos na região que abrange os municípios de Vianópolis, Luziânia e Cristalina, sediados no Estado de Goiás, com limites entre as latitudes $16^{\circ} 15^{\prime}$ e $16^{\circ} 46^{\prime} \mathrm{S}$ e longitudes $47^{\circ} 36^{\prime}$ e $48^{\circ} 30^{\prime}$ W. A altitude média da região está em torno de 1.000 metros (IBGE, 2009).

As sementes foram coletadas em abril de 2008 na Empresa Sementes Brejeiro, sediada em Anápolis-GO. Estas sementes chegaram dos campos de produção em caminhões graneleiros, os quais passaram inicialmente pela recepção, para ser efetuada a pesagem dos mesmos e a amostragem dos lotes para determinação do teor de água com auxílio do determinador de umidade marca Gehaka modelo "Universal". Na oportunidade foi detectado que os teores de água das sementes na colheita variaram de 14 a 15\% base úmida (b.u.).

Após a recepção, as sementes foram submetidas à secagem artificial em secador estacionário com distribuição radial de ar, com temperatura variando de 38 a $42^{\circ} \mathrm{C}$ por uma hora ou até cinco horas, a depender do teor de água presente nas sementes até o teor de água final em torno de $11 \%$ para as diferentes cultivares. O teor de água dos lotes foi determinado por meio do método da estufa $\left(105 \pm 3^{\circ} \mathrm{C}\right.$ por $\left.24 \mathrm{~h}\right)$ (BRASIL, 2009).

Após a secagem, as sementes foram transferidas para sacolas tipo "big bag”, e armazenadas à espera do beneficiamento. O processo de beneficiamento dos diferentes lotes de sementes ocorreu logo após a secagem. Acrescenta-se que o transporte das sacolas "big bag" com as sementes foi feito por máquina empilhadeira até o sistema de beneficiamento, que é constituído das fases de pré-limpeza e limpeza, e o beneficiamento propriamente dito. Entre as diferentes fases do beneficiamento, existiam elevadores de caneca intercalados com altura total de dez metros, e uma queda de três metros por canos com redutores de velocidade, até as máquinas em seqüência.

Para a análise estatística dos dados empregou-se o delineamento experimental inteiramente casualizado (DIC), em esquema fatorial $4 \times 5$, com quatro repetições. Os tratamentos foram constituídos de quatro cultivares de soja (Vencedora, Emgopa-313, Luziânia e Valiosa - transgênica), coletados em cinco pontos de amostragem após as passagens nas diferentes fases do beneficiamento $\left(1^{\circ}-\right.$ secador; $2^{\circ}$ - elevadores de caneca número $1 ; 3^{\circ}$ - elevadores de caneca número $2 ; 4^{\circ}$ - elevadores de caneca número 3 ; e $5^{\circ}$ - espiral). O esquema de obtenção das amostras de sementes seguiu a linha de beneficiamento de soja conforme esquema da (Figura 1). 
Figura 1. Fluxograma ilustrativo das etapas de beneficiamento de sementes de soja na Unidade de Beneficiamento de Sementes da Empresa Brejeiro em Anápolis - GO.
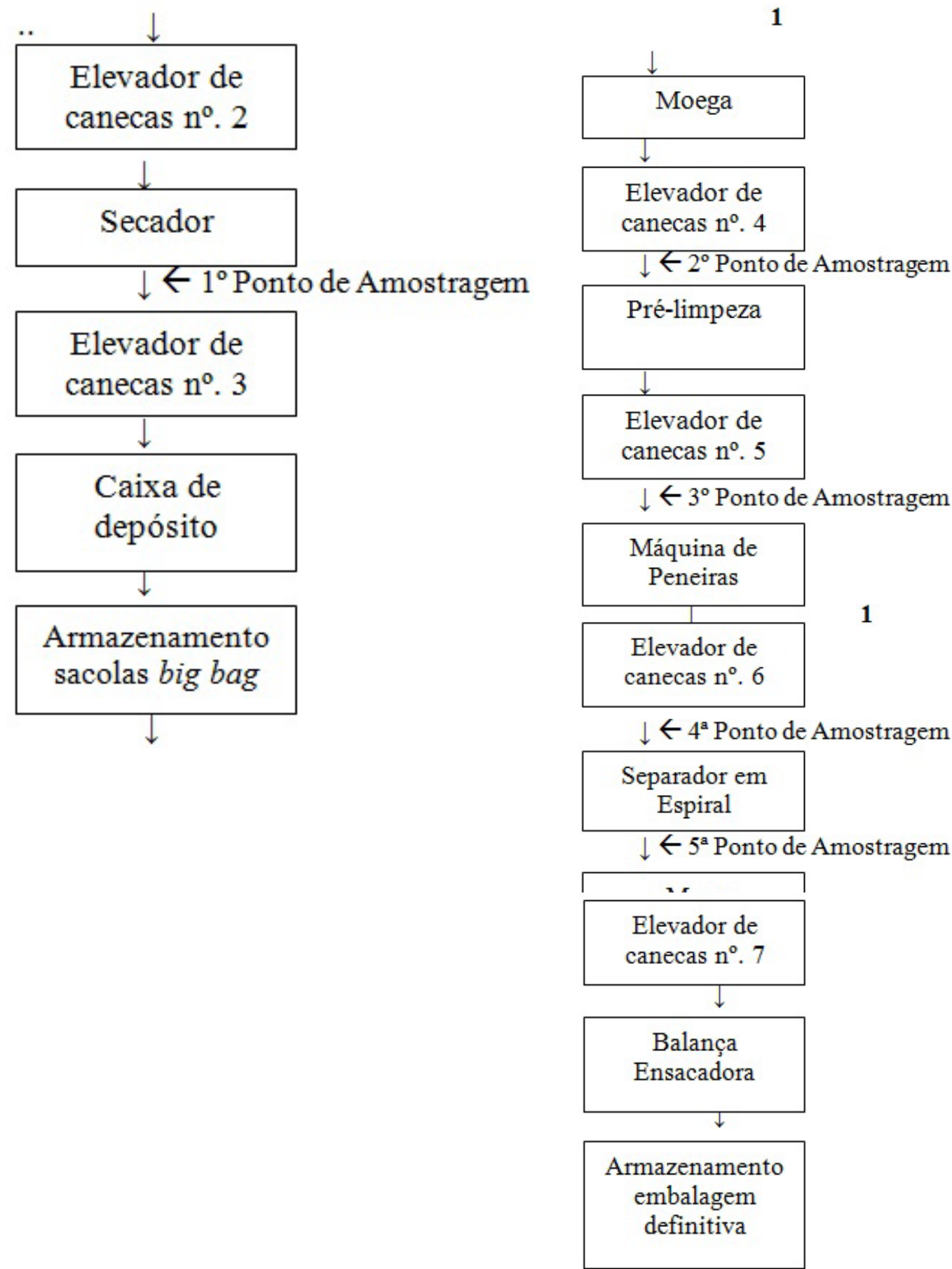

Em cada uma das fases estudadas foram coletadas e embaladas em sacos de papel, com suas devidas amostras de sementes de aproximadamente dois quilos de cada cultivar, com um auxílio de recipiente (copo), identificações e encaminhadas ao Laboratório de Secagem e Armazenamento de Produtos Vegetais da 
Universidade Estadual de Goiás - UEG, situado em Anápolis - GO.

Para a avaliação da qualidade fisiológica das sementes realizou-se os seguintes testes: Teste de Germinação - TG, primeira contagem do TG, envelhecimento acelerado, condutividade elétrica e tetrazólio (viabilidade e vigor).

$\mathrm{O}$ teste de germinação foi realizado com quatro repetições de 50 sementes que foram semeadas em três folhas de papel toalha (germitest), umedecidas com água equivalente a 2,5 vezes o seu peso seco, enroladas e acondicionadas em germinador a $25^{\circ} \mathrm{C}$. A avaliação foi realizada aos oito dias após a instalação (BRASIL, 2009), sendo computada a porcentagem de plântulas normais.

O teste de primeira contagem de germinação foi realizado em conjunto como teste de germinação, computando-se, no quinto dia a porcentagem de plântulas normais (BRASIL, 2009).

Para o envelhecimento acelerado, utilizou-se o método da caixa plástica (gerbox), colocando-se sobre a tela suspensa no interior da caixa plástica, 200 sementes em camada única, contendo no interior da caixa $40 \mathrm{~mL}$ de água. As caixas, tampadas foram colocadas a $41^{\circ} \mathrm{C}$ e $100 \%$ de umidade relativa, por 48 horas (KRZYZANOWSKI; VIEIRA; FRANÇA NETO, 1999), tendo o teor de água das sementes atingido valores em torno de $22 \%$ b.u., quantificado pelo método de estufa à $105^{\circ} \mathrm{C} \pm 3$ (BRASIL, 2009) durante 24 horas. Decorrido esse período, as sementes foram submetidas ao teste de germinação e no quinto dia após a instalação, determinou-se a porcentagem de plântulas normais.

O teste de condutividade elétrica foi realizado conforme a metodologia recomendada por Krzyzanowski, Vieira e França Neto (1999), sendo colocadas 50 sementes/repetição, previamente pesadas, em copos plásticos contendo $75 \mathrm{~mL}$ de água deionizada, e em seguida transferidos para germinador regulado à $25^{\circ} \mathrm{C}$ por 24 horas. Decorrido este período os recipientes foram retirados do germinador e suavemente agitados, e com um auxilio do condutivímetro (TECNOPON modelo CA150), foi efetuada a medição das leituras de condutividade elétrica da solução. Os valores obtidos foram expressos por $\mu \mathrm{S} . \mathrm{cm}-1 . \mathrm{g}-1$.

No teste de tetrazólio as sementes foram hidratadas entre papel toalha, previamente umedecido com água equivalente a 2,5 vezes o peso do papel seco. Em seguida, os rolos de papel permaneceram por 16 horas a $25^{\circ} \mathrm{C}$. À medida que foram completando o período de hidratação, as sementes foram colocadas em solução de $0,075 \%$ de cloreto $2,3,5$ trifenil tetrazólio, por três horas, no escuro a $45^{\circ} \mathrm{C}$. Após o desenvolvimento de cor, as sementes foram lavadas em água corrente e mantidas imersas em água para avaliação. As sementes foram classificadas em porcentagem de sementes viáveis e vigorosas, conforme escala de nota sugerida por Krzyzanowski, Vieira e França Neto (1999).

Os dados foram submetidos à análise de variância, e as diferenças detectadas entre tratamentos, foram discriminadas pelo teste de Tukey, a 5\% de probabilidade.

\section{Resultados e Discussão}

Para a cultivar Vencedora observou-se sementes de menor qualidade fisiológica conforme constatado, especialmente a partir do segundo ponto de amostragem, pelos testes de germinação (Tabela 1), permanecendo assim, abaixo da porcentagem mínima de germinação exigida para a comercialização de sementes de soja no Brasil, que varia atualmente entre 80 a $85 \%$ (BRASIL, 2009). As demais cultivares testadas manteve o equilíbrio desta porcentagem, com destaque para Valiosa, para a qual se observou média de plântulas normais superior a 93\% nos diferentes pontos de amostragem, com exceção do espiral (89\%). Resultados semelhantes foram obtidos por Aguero, Vieira e Bittencourt (1997), Barros e Marcos Filho (1997) e Pereira, Pereira e Fraga (2000) que também obtiveram diferenças na porcentagem de germinação em diferentes lotes de sementes de soja, inclusive com alguns apresentando valores inferiores ao padrão mínimo estabelecido para comercialização. 
Tabela 1. Qualidade fisiológica de sementes de soja submetidas ao beneficiamento.

\begin{tabular}{|c|c|c|c|c|c|c|}
\hline \multirow[t]{2}{*}{ Cultivares } & \multicolumn{5}{|c|}{ Pontos de Amostragem } & \multirow[t]{2}{*}{ Médias } \\
\hline & $\mathbf{1}^{\mathbf{0}}$ & $\mathbf{2}^{\mathbf{0}}$ & $3^{\mathbf{o}}$ & $4^{\circ}$ & $\mathbf{5}^{\circ}$ & \\
\hline & \multicolumn{6}{|c|}{ 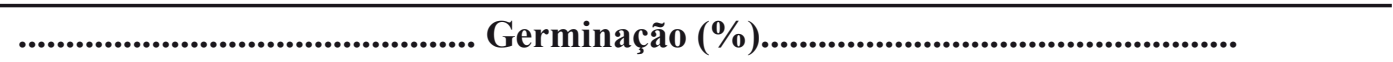 } \\
\hline Vencedora & $88 \mathrm{aA}$ & $75 \mathrm{bB}$ & $73 \mathrm{bB}$ & $71 \mathrm{bB}$ & $73 \mathrm{bB}$ & $76 \mathrm{~b}$ \\
\hline Emgopa 313 & $88 \mathrm{aA}$ & $93 \mathrm{aA}$ & $93 \mathrm{aA}$ & $90 \mathrm{aA}$ & $92 \mathrm{aA}$ & $91 \mathrm{a}$ \\
\hline Luziânia & $87 \mathrm{aA}$ & $92 \mathrm{aA}$ & $91 \mathrm{aA}$ & $89 \mathrm{aA}$ & $92 \mathrm{aA}$ & $90 \mathrm{a}$ \\
\hline Valiosa & $94 \mathrm{aA}$ & $95 \mathrm{aA}$ & $93 \mathrm{aA}$ & $94 \mathrm{aA}$ & $89 \mathrm{aA}$ & $93 \mathrm{a}$ \\
\hline \multirow[t]{2}{*}{ Média } & 89 & 89 & 88 & 86 & 87 & - \\
\hline & \multicolumn{6}{|c|}{. } \\
\hline Vencedora & $88 \mathrm{aA}$ & $70 \mathrm{bB}$ & $67 \mathrm{bB}$ & $66 \mathrm{bB}$ & $68 \mathrm{bB}$ & $72 \mathrm{~b}$ \\
\hline Emgopa 313 & $82 \mathrm{aA}$ & $90 \mathrm{aA}$ & $87 \mathrm{aA}$ & $86 \mathrm{aA}$ & $86 \mathrm{aA}$ & $86 a$ \\
\hline Luziânia & $84 \mathrm{aA}$ & $90 \mathrm{aA}$ & $89 \mathrm{aA}$ & $85 \mathrm{aA}$ & $87 \mathrm{aA}$ & $87 \mathrm{a}$ \\
\hline Valiosa & $91 \mathrm{aA}$ & $92 \mathrm{aA}$ & $89 \mathrm{abA}$ & $92 \mathrm{aA}$ & $79 \mathrm{bA}$ & $89 \mathrm{a}$ \\
\hline \multirow[t]{2}{*}{ Média } & $86 \mathrm{~A}$ & $86 \mathrm{~A}$ & $83 \mathrm{AB}$ & $82 \mathrm{AB}$ & $80 \mathrm{AB}$ & - \\
\hline & \multicolumn{6}{|c|}{ 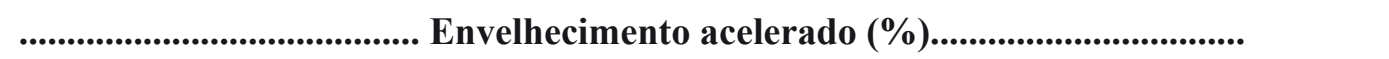 } \\
\hline Vencedora & 67 & 55 & 62 & 53 & 65 & $60 \mathrm{~b}$ \\
\hline Emgopa 313 & 89 & 84 & 85 & 82 & 88 & 86 a \\
\hline Luziânia & 92 & 94 & 90 & 84 & 85 & $89 \mathrm{a}$ \\
\hline Valiosa & 81 & 89 & 86 & 83 & 85 & $85 \mathrm{a}$ \\
\hline \multirow[t]{2}{*}{ Média } & $82 \mathrm{~A}$ & $81 \mathrm{~A}$ & $81 \mathrm{~A}$ & $76 \mathrm{AB}$ & $81 \mathrm{~A}$ & - \\
\hline & \multicolumn{6}{|c|}{ 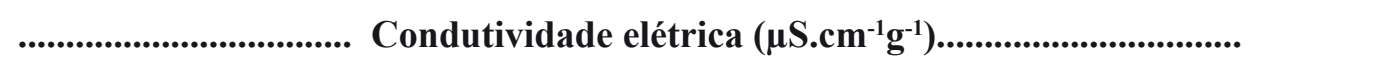 } \\
\hline Vencedora & 51 & 51 & 54 & 56 & 50 & $52 \mathrm{a}$ \\
\hline Emgopa 313 & 40 & 40 & 38 & 36 & 39 & $39 \mathrm{~b}$ \\
\hline Luziânia & 38 & 37 & 35 & 32 & 30 & $34 \mathrm{c}$ \\
\hline Valiosa & 44 & 38 & 41 & 43 & 41 & $41 \mathrm{~b}$ \\
\hline \multirow[t]{2}{*}{ Média } & 43 & 42 & 42 & 42 & 40 & - \\
\hline & \multicolumn{6}{|c|}{ 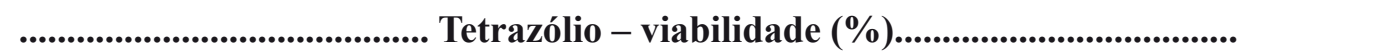 } \\
\hline Vencedora & 100 & 97 & 94 & 96 & 95 & 96 \\
\hline Emgopa 313 & 96 & 96 & 96 & 97 & 98 & 97 \\
\hline Luziânia & 94 & 96 & 97 & 97 & 95 & 96 \\
\hline Valiosa & 97 & 97 & 98 & 97 & 97 & 97 \\
\hline \multirow[t]{2}{*}{ Média } & 97 & 97 & 96 & 97 & 96 & - \\
\hline & \multicolumn{6}{|c|}{ 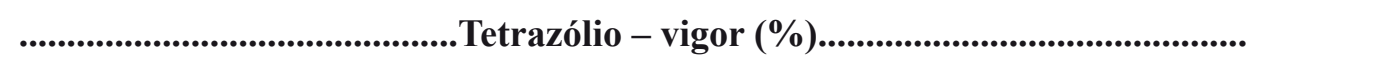 } \\
\hline Vencedora & $93 \mathrm{aA}$ & $90 \mathrm{aA}$ & $67 \mathrm{bB}$ & $68 \mathrm{bB}$ & $64 \mathrm{bB}$ & $76 \mathrm{~b}$ \\
\hline Emgopa 313 & $90 \mathrm{aA}$ & $93 \mathrm{aA}$ & $86 \mathrm{aA}$ & $91 \mathrm{aA}$ & $90 \mathrm{aA}$ & $90 \mathrm{a}$ \\
\hline Luziânia & $84 \mathrm{aA}$ & $89 \mathrm{aA}$ & $89 \mathrm{aA}$ & $86 \mathrm{aA}$ & $86 \mathrm{aA}$ & $87 \mathrm{a}$ \\
\hline Valiosa & $86 \mathrm{aA}$ & $89 \mathrm{aA}$ & $85 \mathrm{aA}$ & $91 \mathrm{aA}$ & $90 \mathrm{aA}$ & $88 \mathrm{a}$ \\
\hline Média & $88 \mathrm{~A}$ & $90 \mathrm{~A}$ & $82 \mathrm{~B}$ & $84 \mathrm{~B}$ & $83 \mathrm{~B}$ & - \\
\hline
\end{tabular}

Médias seguidas pela mesma letra, minúscula na linha e maiúscula na coluna, não diferem entre si pelo teste de Tukey a $5 \%$ de probabilidade. C.Vs. germinação $=5,91 \% ; 1^{\circ}$ contagem $=7,01 \%$; envelhecimento acelerado $=8,37 \%$; condutividade elétrica $=10,05 \%$; tetrazólio - viabilidade $=2,71 \%$ e vigor $=6,30 \%$. 
No caso específico da cultivar Vencedora, a baixa porcentagem de plântulas normais obtida pode estar associada à má qualidade genética das sementes produzidas, como ocorre comumente com material de ciclo precoce na época tradicional de cultivo (semeadura em outubro/novembro) no Estado de Goiás. Esta hipótese esta condizente com resultados obtidos por Medina et al. (1997). Em adição, pôde-se verificar que os danos as sementes foram agravados durante o beneficiamento, uma vez que a germinação após secagem propiciou porcentagem de plântulas normais de $88 \%$, e após o $2^{\circ}$ Ponto de Amostragem os percentuais foram inferiores a 75\% (Tabela 1). Nesse contexto, pode-se afirmar que para maior aprimoramento da qualidade do lote, as sementes da referida cultivar poderiam ser descartadas devido ao baixo percentual de germinação obtida (76\%), pois o seu uso conforme Vanzolini e Carvalho (2002) proporcionaria menor emergência total das plântulas e menor velocidade de emergência. Corrobora para essa afirmativa os relatos de Delouche (2005), para o qual as sementes de baixa viabilidade possuem potencial reduzido de armazenamento.

$\mathrm{Na}$ busca de melhor qualidade fisiológica de sementes de cultivares de soja de ciclo precoce, configura-se como alternativa viável o retardamento da semeadura para início de dezembro em relação à convencional (semeadura em outubro/novembro), como foi verificado em trabalhos de pesquisa conduzidos por Nakagawa, Rosolem e Machado (1984a, 1984b), Nakagawa, Machado e Rosolem (1986) e Pereira, Pereira e Fraga (2000), e até mesmo para final do verão/início do outono, conforme relato de Medina et al. (1997). A justificativa para semeadura tardia das cultivares de soja precoce baseia-se no fato da ausência de chuva na colheita, já que esse fator tem influência direta na qualidade da semente colhida (MARCOS FILHO, 2005). Para o caso da cultivares Emgopa-313, Luziânia e Valiosa, tidas de ciclo médio a tardio, a colheita acontece no final do verão (março/abril), quando normalmente o índice pluviométrico diminui e, portanto, os problemas de chuva da colheita se tornam menos relevantes para se ter sementes de boa qualidade.

Apesar do decréscimo de vigor em sementes da cultivar Vencedora, principalmente após o $2^{\circ}$ Ponto de amostragem, em geral, pôde-se constatar que para as sementes das demais cultivares não houve comprometimento do vigor das mesmas, conforme observado pelos percentuais médios obtidos para plântulas normais, que variou de 80 a 86\% (Tabela 1), fato este confirmado pela não detecção de diferença estatística entre as cultivares nos testes de condutividade elétrica, envelhecimento acelerado e viabilidade (tetrazólio).

A cultivar Vencedora apresentou menores porcentagens médias de vigor de plântulas normais, confirmando os resultados do teste de germinação - TG e do teste primeira contagem TG (Tabela 1). Por outro lado, as cultivares Emgopa-313, Luziânia e Valiosa, de modo geral, apresentaram maiores porcentuais de plântulas normais, não diferindo significativamente entre si.

Apesar da qualidade fisiológica das sementes das diferentes cultivares de soja não ter sido influenciada pelas etapas de beneficiamento, observou-se, em geral, exceto para o $4^{\circ}$ Ponto de amostragem, que as porcentagens de plântulas normais ficaram acima dos padrões mínimos para comercialização de soja (BRASIL, 2009), e que a partir do $2^{\circ}$ Ponto de amostragem há um decréscimo na qualidade das sementes produzidas, o que pode ser atribuído a efeitos danosos na semente provocados pelo beneficiamento, pois segundo Bunch (1962) as sementes mecanicamente danificadas não mantêm $\mathrm{o}$ vigor e a viabilidade durante o armazenamento, devido aos danos interferirem na taxa de respiração e permitirem a entrada de microrganismos.

Em contrapartida, quando se compara as médias gerais das porcentagens de plântulas normais obtidas no teste de envelhecimento acelerado com os resultados do teste de germinação (Tabela 1), nota-se que as sementes submetidas as condições estressantes durante o envelhecimento, propiciaram 
menores porcentagens de plântulas normais. Essa hipótese explica os decréscimos da porcentagem média de plântulas normais obtidas na fase final do beneficiamento, $4^{\circ}$ Ponto de amostragem, onde foi obtido valor de $76 \%$ (Tabela 1), abaixo, portanto, dos padrões mínimos para comercialização que é de $80 \%$.

Como pode ser visto na (Tabela 1), as sementes da cultivar Vencedora liberaram a maior quantidade de exsudados na solução aquosa, permitindo-se inferir sobre a qualidade fisiológica inferior, ou de maior susceptibilidade a danos no tegumento, enquanto a cultivar Luziânia, seguida da Emgopa-313 e Valiosa apresentaram as menores médias, caracterizando dessa forma menores perdas exsudados para a solução aquosa, ou menor dano. Ainda de acordo Vieira (1994), o processo de redução e perda de qualidade está associado à desorganização ou perda de integridade das membranas celulares, fato este diretamente relacionado ao aumento da quantidade de exsudados liberados, evidenciando relação inversa entre a perda de lixiviados e a qualidade das sementes.

Com os pontos de amostragem, apesar da não detecção do efeito significativo para as etapas de beneficiamento, notou-se que houve tendência de acréscimos dos valores de condutividade nos $3^{\circ} \mathrm{e}$ $4^{\mathrm{o}}$ pontos de amostragem, principalmente para a cultivar Vencedora, com valores de 54 e $56 \mu$ s.cm1.g-1 (Tabela 1), confirmando assim, que tais fases do beneficiamento promovem maiores danos à qualidade das sementes.

De acordo com os valores obtidos para condutividade elétrica, pode-se constatar que as sementes da cultivar Vencedora apresentaram leituras acima de $50 \mu \mathrm{s} . \mathrm{cm}-1 . \mathrm{g}-1$ nas etapas de beneficiamento, valor este superior aos das demais cultivares (Tabela 1). Diferenças genotípicas entre cultivares para a liberação de exsudados em sementes de soja também foram detectadas em outros trabalhos realizados por Loeffler, Tekrony e Egli (1988), Carvalho (1994) e Vieira et al. (2002).
Essas diferenças podem estar relacionadas a certas características da própria cultivar, como o teor de lignina no tegumento da semente (ALVAREZ et al., 1997), uma vez que existe uma estreita relação entre o teor de lignina no tegumento de sementes de soja e os resultados do teste de condutividade elétrica (PANOBIANCO et al., 1999), em que os maiores teores do referido composto torna a semente menos susceptível à dano mecânico.

Os valores de condutividade elétrica obtidos para as sementes das diferentes cultivares de soja estão aquém daqueles considerados por Krzyzanowski, Vieira e França Neto (1999) para classificar sementes de baixo vigor $\left(>80 \mu \mathrm{s} . \mathrm{cm}^{-}\right.$ $\left.{ }^{1} . \mathrm{g}^{-1}\right)$, contudo, vale frisar que os referidos autores citam o valor para o teor de água em torno de $13 \%$, e como foi visto o teor de água das sementes das cultivares de soja encontrou-se em torno de $11,0 \%$, justificando assim, os resultados já que as leituras de condutividade elétrica diminuem com o aumento do teor de água das sementes, conforme observaram Vieira et al. (2002), e corrobora com os seus valores encontrados em diferentes safras agrícolas: 45 $\mu \mathrm{s} . \mathrm{cm}^{-1} \cdot \mathrm{g}^{-1}$ (1995) e $53 \mu \mathrm{s} . \mathrm{cm}^{-1} \cdot \mathrm{g}^{-1}$ (1996).

Nesse contexto, pode-se afirmar que os resultados obtidos condizem aos observados em outros testes realizados como o teste de germinação - TG, primeira contagem do TG e envelhecimento acelerado (Tabela 1), e confirmam a inferioridade da cultivar Vencedora em produzir sementes de alta qualidade, notadamente após passarem pelo processo de beneficiamento, comparativamente a demais cultivares em estudo.

$\mathrm{Na}$ avaliação da qualidade fisiológica das sementes, tomando ainda como parâmetro o teste de viabilidade do tetrazólio, pôde-se constatar que todos os lotes de sementes atingiram os padrões mínimos para comercialização, e acima dos valores obtidos nos testes de TG, primeira contagem do TG e de vigor pelo tetrazólio (Tabela 1). Ressaltase, entretanto, que esse teste é reconhecidamente subjetivo, uma vez que a semente apesar de mostrar- 
se viável, pode não ser vigorosa.

$\mathrm{Na}$ (Tabela 1) pode ser verificado que as porcentagens de vigor médio de plântulas normais foram menores para a cultivar Vencedora, notadamente a partir do $3^{\circ}$ ponto de amostragem, devido provavelmente ao dano mecânico sofrido durante a colheita, e que se agravou durante o processo de beneficiamento, conforme constatado nos outros testes aplicados.

No tocante a essa situação, pode-se acrescentar que a identificação do tipo de dano sofrido pela semente é de suma importância na obtenção de material com qualidade. Assim, Peske, Lucca Filho e Barros (2006) classificam os danos mecânicos sofridos pelas sementes em imediato, quando estas se tornam incapazes de germinar logo após sofrerem o dano mecânico, e latentes, quando a germinação não é prontamente afetada, mas o vigor e o potencial de armazenamento são reduzidos. Nos dois casos, a identificação do tipo de danos, seja no campo ou nas etapas de beneficiamento, é relevante para identificar lotes com comportamento superior. Dessa forma, o uso do tetrazólio comumente empregado na análise de sementes se tornou um teste eficaz por permitir classificar lotes de sementes de soja com diferentes graus de deterioração quanto à viabilidade e ao vigor.

Em contrapartida, as sementes mais vigorosas foram oriundas das cultivares Emgopa-313, Luziânia e Valiosa, com percentuais de vigor, na maioria dos casos, superiores a $85 \%$, mostrando assim a superioridade das mesmas quando comparadas a cultivar Vencedora em, praticamente, todas as etapas de beneficiamento.

\section{Conclusões}

As sementes das cultivares de soja Emgopa-313, Valiosa, e Luziânia apresentam maior viabilidade, comparativamente às sementes da cultivar Vencedora, em todas as etapas do beneficiamento.

Para as sementes da cultivar Vencedora, o grande número de elevadores de caneca no decorrer das etapas de secagem e no beneficiamento propicia aumento na porcentagem de dano mecânico à semente.

\section{Agradecimentos}

A Empresa Sementes Brejeiro - Anápolis (GO) pela concessão das sementes, e a Capes pela ajuda financeira para aquisição de insumos e equipamentos de laboratório.

\section{Referências}

AGUERO, J. A. P.; VIEIRA, R. D.; BITTENCOURT, S. R. M. Avaliação da qualidade fisiológica de sementes de cultivares de soja. Revista Brasileira de Sementes, Brasília, v. 19, n. 2, p. 254-259, 1997.

ALVAREZ, P. J. C.; KRZYZANOWSKI, F. C.; MANDARINO, J. M. G.; FRANÇA NETO, J. B. Relationship between soybean seed coat lignin content and resistance to mechanical damage. Seed Science and Technology, Zürich, v. 25, n. 2, p. 209-214, 1997.

ANDRADE, E. T.; CORRÊA, P. C.; ALVARENGA, E. M.; MARTINS, J. H. Efeito do impacto mecânico controlado sobre a qualidade fisiológica de sementes de feijão. Engenharia na Agricultura, Jaboticabal, v. 7, n. 3 , p. 148-159, 1999.

BARROS, A. S. R.; MARCOS FILHO, J. Testes para avaliação rápida do vigor de sementes de soja. Revista Brasileira de Sementes, Brasília, v. 19, n. 2, p. 288-294, 1997.

BRASIL. Ministério da Agricultura, Pecuária e Abastecimento. Regras para análise de sementes. Ministério da Agricultura, Pecuária e Abastecimento. Secretaria de Defesa Agropecuária. Brasília, DF: MAPA/ ACS, 2009. 395 p.

BUNCH, H. D. Problems in seed processing. Seed Word, Chicago, v. 90, n. 9, p. 9-11, 1962.

CARBONELL, S. A.; KRZYZANOWSKI, E. C.; OLIVEIRA, M. C. N.; FONSECA-JUNIOR, N. S. Teor de umidade das sementes de soja e métodos de avaliação do dano mecânico provocado no teste de pêndulo. Pesquisa Agropecuária Brasileira, Brasília, v. 28, n. 1, p. 1277-1285, 1993.

CARBONELL, S. A. M.; KRZYZANOWSKI, E. C. The pendulun test for screening soybean genotypes to 
mecanical damage. Seed Science and Technology, Zürich, v. 23, v. 2, p. 331-339, 1995.

CARVALHO, M. V. Determinação do fator de correção para condutividade elétrica em função do teor de água de sementes de soja [Glycine max (L.) Merrill]. 1994. Dissertação (Mestrado em Agronomia) - Universidade Estadual Paulista Júlio de Mesquita Filho, Jaboticabal.

CARVALHO, N. M.; NAKAGAWA, J. Sementes: ciência, tecnologia e produção. 4. ed. Jaboticabal: FUNEP, 2000. 588 p.

COMPANHIA NACIONAL DE ABASTECIMENTO - CONAB. $12^{\circ}$ Levantamento de grãos 2110: soja. Comparativo da área, produção e produtividade - safras 2008/09 e 2009/10. Disponível em: <http://www.conab. gov.br>. Acesso em: 11 set. 2010.

COSTA, A. V.; KUENEMAN, E. A.; MONTEIRO, P. M. E. D. Varietal differences in soybean forresistence to physical damage off seed. Soybean Genetics Newslestter, East Lansing, v. 14, n. 1, p. 73-76, 1987.

DELOUCHE, J. D. Pensamentos e reflexões sobre armazenamento de sementes III. Revista Seed News, Pelotas, v. 9, n. 5, p. 12-14, 2005.

FLOR, E. P. O.; CÍCERO, S. M.; FRANÇA NETO, J. B.; KRZYZANOWSKI, F. C. Avaliação de danos mecânicos em sementes de soja por meio da análise de imagem. Revista Brasileira de Sementes, Brasília, v. 26, n. 1, p. 68-76, 2004.

INSTITUTO BRASILEIRO DE GEOGRAFIA E ESTATÍSTICA - IBGE. Canais: cidades. Disponível em: $<$ http://www.ibge.gov.br/cidadesat/topwindow.htm?1>. Acesso em: 02 abr. 2009.

KRZYZANOWSKI, F. C.; VIEIRA, R. D.; FRANÇA NETO, J. B. Vigor de sementes: conceitos e testes. Londrina: Associação Brasileira de Tecnologia de Sementes, 1999.

LOEFFLER, T. M.; TEKRONY, D. M.; EGLI, D. B. The bulk conductivity test as an indicator of soybean seed quality. Journal of Seed Technology, Lansing, v. 12, n. 1, p. 37-53, 1988.

MACHADO, R. T. M. Rastreabilidade, tecnologia da informação e coordenação de sistemas agroindustriais. 2000. Dissertação (Mestrado em Administração) Universidade de São Paulo, São Paulo.

MARCOS FILHO, J. Fisiologia de sementes de plantas cultivadas. Piracicaba: Fealq, 2005. 495 p.

MEDINA, P. F.; RAZERA, L. F.; MARCOS FILHO, J.; BORTOLETTO, N. Produção de sementes de cultivares precoces de soja em duas épocas e dois locais paulistas: II. Qualidade fisiológica. Bragantia, Campinas, v. 56, n.
2, p. 305-315, 1997

NAKAGAWA, J.; MACHADO, J. R.; ROSOLEM, C. A. Efeito da densidade de plantas e da época de semeadura na produção e qualidade de sementes de soja. Revista Brasileira de Sementes, Brasília, v. 8, n. 3, p. 99-112, 1986.

NAKAGAWA, J.; ROSOLEM, C. A.; MACHADO, J. R. Desempenho de sementes de soja originárias de culturas estabelecidas em diferentes épocas. Revista Brasileira de Sementes, Brasília, v. 6, n. 3, p. 61-76, 1984 b.

Efeito da época de semeadura na qualidade de sementes de três cultivares de soja, em Botucatu-SP. Revista Brasileira de Sementes, Brasília, v. 6, n. 1, p. 25 38, 1984a.

NAPLAVA, V.; WEINGARTMANN, H.; BOXBERGER, J. Quality research of seed maize during drying and conditioning. 1. Mechanical damage. Bodenkultur, Vienna, v. 45, n. 4, p. 333-348, 1994.

PACHECO, C. A. P.; CASTOLDI, F. L.; ALVARENGA, E. M. Efeito do dano mecânico na qualidade fisiológica e na capacidade de expansão de sementes de milho pipoca. Revista Brasileira de Sementes, Brasília, v. 18, n. 2, p. 267-270, 1996.

PANOBIANCO,M.; VIEIRA, R.D.; KRZYZANOWSKI, F. C.; FRANÇA NETO, J. B. Electrical conductivity of soybean seed and correlation with seed coat lignin content. Seed Science and Technology, Zürich, v. 27, n. 3, p. 945-949, 1999.

PAULSEN, M. R.; NAVE, W. R. Soybean seed quality as affected by impact damage. Transactions of the American Society of Agricultural Engineers, Saint Joseph, v. 24, n. 6, p. 1577-1589, 1981.

PEREIRA, E. B. C.; PEREIRA, A. V.; FRAGA, A. C. Qualidade de sementes de cultivares precoces de soja produzidas em três épocas. Pesquisa Agropecuária Brasileira, Brasília, v. 35, n. 7, p. 1653-1662, 2000.

PESKE, S.T.; LUCCA FILHO, O. A.; BARROS, A. C. S. A. Sementes: fundamentos científicos e tecnológicos. 2. ed. Brasília: Ed. Universitária/UFPel, 2006. 470 p.

PESKE, S. T.; VILLELA, F. A. Secagem de sementes. In: PESKE, S. T.; ROSENTHAL, M. D.; ROTA, G. R. M. Sementes: fundamentos científicos e tecnológicos. Brasília: UFPEL, 2003. p. 281-320.

PETERSON, J. M.; PERDOMO, J. A.; BURRIS, J. S. Influence of kernel position, mechanical damage and controlled deterioration on estimates of hybrid maize seed quality. Seed Science and Technology, Zürich, v. 23, n. 3, p. 647-657, 1995.

VANZOLINI, S.; CARVALHO, N. M. Efeito do vigor 
de sementes de soja sobre o seu desempenho em campo. Revista Brasileira de Sementes, Brasília, v. 24, n. 1, p. 33-41, 2002.

VIEIRA, R. D. Teste de condutividade elétrica. In.:VIEIRA, R. D.; CARVALHO, N. M. (Ed.). Testes de vigor em sementes. Jaboticabal: FUNEP/UNESP, 1994. p. 103-132.

VIEIRA, R. D.; PENARIOL, A. L.; PERECIN, D.; PONABIANCO, M. Condutividade elétrica e teor inicial das sementes de soja. Pesquisa Agropecuária Brasileira, Brasília, v. 37, n. 9, p. 1333-1338, 2002. 
